JURNALYOGA DAN KESEHATAN

JURUSAN YOGA KESEHATAN

FAKULTAS BRAHMA WIDYA

IHDN DENPASAR
Vol. 3 No. 2 September 2020

ISSN : 2621-0185 (Cetak)

ISSN : 2722-9440 (Online)

http://ejournal.ihdn.ac.id/index.php/jyk

\title{
Pelatihan Hatha Yoga Bagi Dosen dan Pegawai di Universitas Ngurah Rai Denpasar
}

\author{
Ida Ayu Dwidyaniti Wira
}

Institut Pariwisata dan Bisnis Internasional Bali

Email: dwidyanitiwira88@gmail.com

Diterima tanggal 18 Juli 2020, diseleksi tanggal 15 Agustus 2020, dan disetujui tanggal 29 Agustus 2020

\section{ABSTRACT:}

Hinduism has many teachings related to ethics, morals and health, one of which is the teachings of Hatha yoga. In this case the Hatha Yoga training is considered very important in efforts to improve ethics, morals and public health, especially for lecturers and staff at Ngurah Rai University, Denpasar. This research is in the form of a qualitative design. Data were collected using observation techniques, interview techniques and literature techniques. After the data is collected, the data are analyzed by descriptive qualitative and interpretative descriptive methods. Based on this analysis, conclusions are obtained as a result of the study, as follows: (1) The process of implementing the Hatha Yoga training consists of opening greetings and joint prayers, pranayama exercises, motion warm-ups, Surya Namaskara motion exercises, loose asanas exercises, Savasana, Meditation and Hasya Yoga (Closing). (2) The benefits of Hatha Yoga training are to improve physical, mental and spiritual health.

Keywords: Training; Hatha Yoga; lecturers and staff

\section{ABSTRAK:}

Agama Hindu memiliki banyak ajaran-ajaran yang terkait dengan etika, moral dan kesehatan salah satunya adalah ajaran Hatha yoga. Dalam hal ini pelatihan Hatha Yoga dipandang sangat penting dalam upaya meningkatkan etika, moral dan kesehatan masyarakat khususnya bagi dosen dan pegawai di Universitas Ngurah Rai Denpasar. Penelitian ini berbentuk rancangan kualitatif. Data dikumpulkan dengan menggunakan teknik observasi, teknik wawancara dan teknik kepustakaan. Setelah data terkumpul, data dianalisis dengan metode deskriptif kualitatif dan deskriptif interpretative. Berdasarkan analisis tersebut, diperoleh simpulan sebagai hasil penelitian, sebagai berikut: (1) Proses pelaksanaan pelatihan Hatha Yoga terdiri dari Salam pembuka dan doa bersama, latihan pranayama, pemanasan gerak, latihan gerak Surya Namaskara, latihan asanas lepas, Savasana, Meditasi dan Hasya Yoga (penutup). (2) Manfaat pelatihan Hatha Yoga yaitu untuk menngkatkan kesehatan fisik, mental dan spiritual.

Kata Kunci: Pelatihan; Hatha Yoga; Dosen dan Pegawai 


\section{PENDAHULUAN}

Ajaran yoga pertama kali diperkenalkan oleh Maharsi Patanjali dalam karyanya yang berjudul Yoga Sutra. Beliau pendiri sistem ajaran yoga, walaupun unsur-unsur ajarannya sudah ada sebelum karya tulis ini. Kemudian menyusullah buku-buku komentar atas ajaran beliau seperti byasabhasya tulisan byasa, nitti tulisan bhijaraja dan lain-lain. Komentar-komentar ini menguraikan ajaran yoga Rsi Patañjali yang di tulis dalam kalimat-kalimat pendek yang padat isinya. Ajaran yoga adalah anugrah yang luar biasa besarnya dari Rsi Patañjali kepada siapa saja yang melaksanakan hidup kerohanian. Ajaran ini merupakan bantuan kepada mereka yang ingin menginsyafi kenyataan adanya roh sebagai asas yang bebas, bebas dari tubuh indrianya dan pikiran yang terbatas (Suadnyana, 2020).

Kata yoga artinya ialah hubungan, hubungan antara roh yang berperibadi dengan roh yang universal yang tidak berpribadi. Tetapi Rsi Patanjali mengartikan yoga sebagai citta vrtti nirodhah yaitu penghentian geraknya pikiran. Seluruh kitab yoga sūtra karya Rsi Patanjali itu dibagi atas empat bagian dengan 194 sutra. Bagian pertama disebut samadhipada. Isinya ialah tentang sifat, tujuan dan bentuk ajaran yoga. Bagian kedua disebut sadhanapada. Isinya tentang pelaksanaan ajaran yoga seprti cara mencapai samadhi tentang kedudukan, tentang karma phala dan sebagainya. Bagian ketiga disebut vibhutipada yang mengajarkan tentang segi batiniah ajaran yoga dan juga tentang kekuatan gaib yang didapat karena melaksanakan praktek yoga. Bagian keempat disebut kaivalyapada, melukiskan tentang alam kelepasan dan kenyataan roh yang mengatasi yang mengatasi alam duniawi (Sura dan sukayasa, 2009: 18).

Somvir (2009:13) menyatakan Yoga membantu manusia dalam mengendalikan diri, mengendalikan perbuatan, ucapan dan membersihkan badan melalui pranayama. Manusia hendaknya menggunakan kedua tangannya untuk melakukan perbuatan baik sehingga jika kematian tiba ia tidak lagi merasa takut atau menangis tetapi sudah siap menghadapinya penuh bahagya dan tersenyum. Ajaran yoga bersifat universal jauh dari pengaruh Agama, sekte, ataupun kelompok tertentu. Untuk itu ajaran yoga memiliki tujuan yang sangat mulia yaitu:

a. Tujuan riil (jangka pendek) orang belajar yoga adalah agar menjadi manusia rahayu: sehat dan bahagia lahir-batin, tidak sakit-sakitan, terhindar dari penderitaan. Agar menjadi manusia sadar dapat melaksanakan tugas hidup sebagaimana mestinya.

b. Tujuan ideal (jangka panjangnya) adalah agar mendapat pengalaman religious, yakni mengetahui, memahami, dan mengalami kemanunggalan dengan sang jati diri. Manunggalnya ātman 'roh individu' dengan Atman atau Brahman 'Roh Semesta, Tuhan'. Akan tetapi, bagi pengagum daya magis, siddhi 'kekuatan supranatural' itulah dijadikan tujuan utamanya, maka ia melaksanakan yoga yang khas. 
Ajaran Yoga saat ini telah berkembang di seluruh pelosok nusantara khususnya untuk umat yang beragama Hindu. Ajaran yoga diterapkan melalui sekolah-sekolah, perguruan tinggi, pasraman, dan perkumpulan-perkumpulan yoga yang ada di masyarakat. Penerapan yoga di suatu tempat atau daerah tidaklah sama, semua memiliki ciri khas masing-masing sesuai dengan perkembangan ajaran yoga saat ini namun tetap berpatokan pada inti dari ajaran yoga tersebut.

Hatha Yoga merupakan salah satu ajaran yoga yang paling banyak diterapkan di masyarakat karena sangat erat kaitannya dengan pendidikan fisik, mental dan spiritual. Konsep hatha yoga diperkenalkan dalam dua teks buku Hathayogapradipika dan grandha samhita juga bersumber pada sutra Patanjali. Hatha yoga menerima asana gerakan badan, latihan pernafasan dan meditasi dhayana dari sutra Patanjali, sehinga konsep hatha yoga tidak jauh dari Patanjali (Somvir, 2009: $31)$.

Universitas Ngurah Rai Denpasar merupakan bagian dari masyarakat secara umum dimana orang-orang di dalamnya merupakan kaum intelektual untuk itu Universitas Ngurah Rai Denpasar mengadakan pelatihan hatha yoga bagi dosen dan pegawai yang dilakukan secara rutin setiap hari kamis pagi di Universitas Ngurah Rai Denpasar. Kegiatan tersebut merupakan bagian dari upaya lembaga dalam meningkatkan kualitas dosen dan pegawai di Universitas Ngurah Rai Denpasar sekaligus mengantisifasi terjadinya krisis etika dan moral dikalangan lembaga kampus. Selain hal tersebut Universitas Ngurah Rai Denpasar sebagai lembaga pendidikan juga berupaya untuk mensosialisasikan ajaran hatha yoga pada masyarakat sehingga melalui pelatihan hatha yoga masyarakat mampu mengatasi permasalahan-permasalahan yang terkait dengan etika, moral dan kesehatan masyarakat. Dari latar belakang masalah di atas adapun judul yang diangkat dalam penelitian ini yaitu pelatihan hatha yoga bagi dosen dan pegawai di Universitas Ngurah Rai Denpasar.

\section{PEMBAHASAN}

\subsection{Proses Pelaksanaan Pelatihan Hatha Yoga bagi Dosen dan Pegawai di Universitas Ngurah Rai Denpasar.}

Pelatihan hatha yoga bagi dosen dan pegawai di Universitas Ngurah Rai merupakan kegiatan non kurikuler atau kegiatan ekstra kurikuler sehingga kegiatan ini tidak dimasukkan dalam kurikulum khusus. Peserta dari pelatihan hatha yoga ini ialah dosen dan pegawai di lingkungan Universitas Ngurah Rai, kegiatan ini bersifat tanpa paksaan khusus untuk mereka yang ingin membangun sikap mental dan spiritual. Proses pelatihan hatha yoga ini dilaksanakan setiap hari kamis pagi jam 09.00 - selesai. Instruktur dari pelatihan hatha yoga ini merupakan dosen tetap di lingkungan Universitas Ngurah Rai. Proses pelaksanaan pelatihan hatha yoga bagi 
Dosen dan Pegawai di Universitas Ngurah Rai Denpasar dilaksanakan setiap hari kamis pagi di Universitas Ngurah Rai Denpasar. Dalam proses pelaksanaan pelatihan hatha yoga bagi dosen dan pegawai di Universitas Ngurah Rai Denpasar ada delapan tahapan yang di lakukan, adapun tahapan tersebut yaitu: (1) Salam pembuka dan doa bersama, (2) Latihan pranayama, (3) Pemanasan gerak, (4) Latihan gerak surya namaskara, (5) Latihan asanas lepas, (6) Savasana, (7) Meditasi dan (8) Hasya yoga (penutup).

\section{Salam Pembuka dan Doa Bersama}

Untuk mengawali kegiatan pelatihan hatha yoga, pertama-tama pembina yoga memberi salam kepada peserta yang mengikuti pelatihan hatha yoga dengan mengucapkan salam $\mathrm{Om}$ Swastyastu dan salam Namaste. Selanjutnya peserta pelatihan hatha yoga diajak untuk berdoa bersama-sama untuk memohon perlindungan agar kegiatan pelatihan Hatha yoga berjalan lancer tanpa halangan.

\section{Latihan Pranayama}

Pranayama merupakan latihan pernapasan di dalam Yoga yang bermanfaat menguatkan organ internal serta membersihkan diri dari dalam sehingga pikiran akan menjadi tenang. Beberapa teknik pranayama yang dilakukan dalam tahapan ini, yaitu: Nādi Sodhana Prānāyāma; 2) Abhyantar Prānāyāma; 3) Bahyantar Prānāyāma; 4) Anulom Vilom Prānāyāma; 5) Bhramari Prānāyāma; 6) Kapālabhāti Prānāyāma; 7) Bhastrika Prānāyāma

\section{Pemanasan Gerak}

Pemanasan gerak dilakukan untuk melemaskan otot-otot tubuh agar tidak kaku sehingga tidak cedera ketika melakukan gerak asanas. Adadapun gerakan pemanasan yang dilakukan dalam tahapan ini, yaitu pelemasan kaki, Pelemasan Tangan, Pelemasan Kepala

\section{Latihan Gerak Surya Namaskara}

Surya Namaskar merupakan penghormatan kepada matahari sebagai sumber energi kehidupan. Surya Namaskar merupakan rangkaian asana yang dilakukan secara vinyasa (mengalir), gerakan ini terdiri dari 12 gerakan asana yang mengikuti tarikan dan embusan napas. Adapun rangkaian gerak Surya Namaskara yang dilakukan dalam tahapan ini, yaitu: 1) Pranamasana Atau Posisi Berdoa; 2) Hasta Utanāsana Atau Posisi Tangan Diangkat; 3) Padahastāsana atau Posisi Membungkuk/Mencium Lutut; 4) Asva Sancalāsana Atau Posisi Menunggang Kuda; 5) Parvatāsana Atau Postur Gunung; 6) Astangag Namaskara Atau Posisi Sujud Dengan Delapan Anggota Badan; 7) Bhujangāsana Atau Postur Ular Kobra; 8) Parvatāsana Atau Postur Gunung; 9) Asva Sancalāsana Atau Postur Menunggang Kuda; 10) Padahastāsana Atau Posisi Membungkuk/Mencium Lutut; 11) Hasta Utanāsana Atau Posisi Mengangkat Tangan; 12) Pranamāsana Atau Posisi Berdoa. 


\section{Latihan Asanas Lepas}

Setelah melakukan gerakan Surya Namaskara selanjutnya dilanjutkan dengan melakukan beberapa asanas lepas untuk meningkatkan kualitas gerak dan mendapatkan manfaat yang lebih baik lagi. Asanas lepas dilakukan secara berurutan mulai dari posisi berdiri, duduk, tidur dan telungkup. Adapun asanas lepas yang dilakukan pada tahapan ini, yaitu:

\section{a. Asanas Posisi Berdiri}

\section{1) Tadāsana}

Tekniknya : Ambil posisi berdiri dengan kedua tangan berada di samping badan, jaga keseimbangan tubuh kiri dan kanan, naikkan tangan lurus ke atas dan cakupkan kedua telapak tangan di atas kepala, pandangan pokus pada satu titik kedepan. Tarik nafas lalu rentangkan tangan, bahu dan dada ke atas, kedua tumit di angakat (berdiri dengan jari-jari kaki) hingga berat badan berada pada jari-jari kaki. Tahan nafas dan diam beberapa saat dalam posisi ini, setelah dirasa cukup turunkan tumit sambil membuang nafas kemudian kembali ke posisi awal.

\section{2) Trikonāsana}

Tekniknya : Ambil posisi berdiri lalu renggangkan kedua kaki, letakkan tangan kiri di pinggang kemudian tarik nafas bawa tangan kanan ke atas lalu rebahkan ke samping kiri, pandangan mengarah ke depan. lakukan tehnik ini bergantian kiri dan kanan.

\section{3) Pascimottanasana Posisi Berdiri}

Tekniknya : Ambil posisi berdiri lalu tarik nafas kemudian hembuskan nafas dan bungkukkan badan ke depan, pegang ibu jari kaki dengan tangan, tahan napas beberapa saat kemudian perlahan kembali ke posisi awal.

\section{4) Dhruvāsana}

Tekniknya : Ambil posisi berdiri lalu letakkan kaki kanan pada pangkal paha kiri kemudian tarik napas sambil membawa tangan ke atas dan cakupkan kedua tangan diatas kepala, tahan napas beberapa saat, pandangan fokus pada satu titik kemudian hembuskan napas dan kembali ke posisi semula. lakukan tehnik ini bergantian kiri dan kanan.

\section{5) Natarajāsana}

Tekniknya : Berdiri dalam posisi tegak, pegang kaki kanan dengan tangan kanan, tarik nafas lalu tarik kaki kanan sampai melengkung dan tangan kiri lurus ke depan sebagai penyeimbang, pertahankan beberapa saat dan hembuskan nafas kembali ke posisi semula. lakukan tehnik ini bergantian kiri dan kanan. 


\section{6) Garudāsana}

Tekniknya : Berdiri dalam posisi tegak, lipat kaki kiri di belakang kaki kanan demikian juga tangan kiri ke tangan kanan. Tarik napas tundukkan kaki sedikit ke bawah, tahan beberapa saat kemudian perlahan hembuskan napas dan kembali ke posisi semula. Lakukan tehnik ini bergantian kiri dan kanan.

\section{b. Asanas Posisi Duduk}

\section{1) Pascimottanasana Posisi Duduk}

Tekniknya : Duduklah dalam posisi kedua kaki lurus ke depan, tarik nafas kemudian hembuskan sambil mencium lutut, kedua tangan memegang jari-jari kaki lalu tahan nafas sesuai kemampuan. Tarik nafas pada saat kembali pada posisi awal kemudian hembuskan.

\section{2) Akarnadhanurasana}

Tehnik : Duduklah dengan kedua kaki lurus pegang ibu jari kaki kiri dengan tangan kanan kemudian ibu jari kaki kanan dipegang dengan tangan kiri, tarik napas dan mulai tarik kaki kiri sampai menyentuh telinga, tahan napas lalu perlahan hembuskan nafas dan kembali ke posisi awal. Lakukan tehnik ini bergantian kiri dan kanan.

\section{3) Gomukhasan}

Tekniknya : Duduklah dalam posisi kedua kaki lurus kemudian lipat kaki kanan dan letakkan kaki kiri di atas kaki kanan, tangan kiri di arahkan ke atas dan tangan kanan mengarah ke bawah, pertemukan kedua telapak tangan di belakang pundak kemudian tarik lalu tahan beberapa saat dan perlahan keluarkan nafas kembali ke posisi semula. Lakukan tehnik ini bergantian kiri dan kanan.

\section{4) Marichyāsana}

Tekniknya : Duduklah dalam posisi kedua kaki lurus kemudian lipat kaki kanan dan letakkan kaki kiri di atas kaki kanan, tarik nafas terlebih dahulu kemudian buang nafas dan putar badan ke samping kiri, sebrangkan tangan kana dan pegang pergelanagn kaki kiri, tangan kiri dibawa ke belakan dan pandangan mengarah ke belakang, tahan beberapa saat dan tarik nafas kembali ke posisi semula. Lakukan tehnik ini bergantian kiri dan kanan.

\section{5) Ustrasana}

Tekniknya : Berdiri diatas kedua lutut, tarik nafas lalu pegang tumit kanan dan tumit kiri dengan kedua tangan, lengkungkan badan dan pandangan mengarah ke atas, tahan nafas sesaat dan hembuskan napas sambil kembali pada posisi awal. 


\section{c. Asanas Posisi Tidur Tengadah}

\section{1) Uttanapadasana}

Tekniknya : Ambil sikap tidur tengadah, kedua kaki dirapatkan, letakkan tangan di bawah paha telapak tangan menghadap ke bawah. Perlahan tarik napas angkat kedua kaki setinggi 30 derajat lalu tahan sesaat kemudian turunkan kaki sambil hembuskan napas.

\section{2) Halasan}

Tekniknya : Ambil posisi tidur tengadah lalu angkat kedua kaki bawa ke belakang sampai ujung jari kaki menyentuh lantai, kedua kaki dalam posisi lurus, bernafas normal, pertahankan beberapa saat lalu kembali ke posisi semula.

\section{3) Sarvangasana}

Tekniknya : Ambil posisi tidur tengadah, kedua kaki diangkat keatas dengan bantuan kedua tangan di pinggang hingga lutut dan pergelangan kaki lurus ke atas, bernafas normal, pertahankan beberapa saat dan kembali ke posisi semula.

\section{4) Pavanmuktāsana}

Tekniknya : Ambil posisi tidur tengadah, tekuk kaki kanan dan rangkul dengan kedua tangan, tarik nafas lalu angakat kepala dan cium lutut kanan, tahan nafas sesaat dan hembuskan kembali ke posisi semula. Lakukan tehnik ini bergantian kiri dan kanan.

\section{5) Cakrāsana}

Tekniknya : Ambil posisi tidur tengadah, tekuk kedua kaki sampai menempel di pantat, letakkan kedua tangan diatas pundak, perlahan tarik nafas dan angkat badan ke atas membentuk setengah lingkaran ( cakra ) tahan napas dan perlahan hembuskan napas untuk kembali pada posisi awal.

\section{d. Asana Posisi Tidur Telungkup}

\section{1) Bhujangāsan}

Tekniknya : Ambil posisi tidur telungkup, tarik napas lalu angkatlah dada dan kepala ke atas, kedua tangan lurus, pandangan mata lurus ke atas sampai punggung melengkung, tahan beberapa saat dan hembuskan nafas kembali ke posisi semula.

\section{2) Salabhāsana}

Tekniknya : Ambil posisi tidur telungkup, letakkan ke dua telapak tangan menghadap ke bawah di bawah paha. Tarik nafas angkat kedua kaki dengan sudut 30 derajat, tahan beberapa saat kemudian hembuskan perlahan dan kembali ke posisi semula

\section{3) Dhanurasana}

Tekniknya : Ambil posisi tidur telungkup, tekuk kedua kaki dan pegang pergelangan kaki dengan kedua tangan, Sambil menarik nafas angkat kaki ke atas sampai badan 
melengkung membentuk busur, tahan nafas beberapa saat dan keluarkan naafs kembali ke posisi semula.

\section{Savasana}

Setelah selesai melakukan semua gerakan asana maka tahap selanjutnya adalah melakukan relaksasi. Relaksasi merupakan bagian dari asana dan sama pentingnya dengan asanaasana yang lain. Relaksasi dilakukan melalui sikap savasana, adapun tehniknya ialah tidurlah di atas lantai dengan beralaskan matras dengan posisi kaki terbuka selebar bahu kedua tangan berada lurus diantara badan dengan telapak tangan menghadap ke atas. Pejamkan mata dan kendorkan semua otot dalam tubuh, lepaskan ketegangan pada otot-otot bagian tubuh mulai dari ujung kaki sampai kepala.

\section{Meditasi}

Meditasi merupakan tahapan ke tujuh dalam pelatihan Hatha yoga bagi Dosen dan Pegawai di Universitas Ngurah Rai. Pada tahapan ini peserta diajak untuk mendekatkan diri kepada Tuhan dan merenungkan Tuhan dengan mengucapkan doa Aum. Duduklah dalam sikap padmasana atau siddhasana dengan mata terpejam, letakkan tangan diatas lutut dalam sikap Jayan Mudra( ibu jari bertemu dengan telunjuk) kemudian ucapkan nama tuhan sesuai dengan kepercayaan atau mengucapkan doa Aum sebanyak 11 kali. Kemudian renungkan nama Tuhan melalui pikiran dengan berkonsentrasi diantara kedua alis mata selama beberapa menit. Setelah selesai kemudian gosokkan kedua belah telapak tangan lalu tempelkan di mata dan seluruh wajah sebanyak tiga kali.

\section{Hasya Yoga (penutup)}

Hasya yoga merupakan kegiatan akhir dari pelatihan Hatha yoga bagi Dosen dan Pegawai di Universitas Ngurah Rai Denpasar. Hasya Yoga dilakukan dengan tujuan agar pada kegiatan pelatihan Hatha yoga diakhiri dengan rasa senang, bahagia dan selalu bersyukur atas karunia yang diberikan oleh Tuhan. Tekniknya: duduk dalam sikap vajrasana atau siddhasana kemudian tarik nafas bawa tangan ke atas lalu hembuskan nafas dan tertawa sekuatnya. Lakukan teknik tersebut sebanyak tiga kali.

\subsection{Manfaat Pelatihan Hatha yoga bagi Dosen dan Pegawai di Universitas Ngurah Rai Denpasar.}

\section{Manfaat Bagi Fisik}

Jaringan kelenjar endokrin yang penting tersebut dikendalikan dan diatur sehingga sejumlah hormone yang berbeda dikeluarkan dari semua kelenjar dalam tubuh. Hal ini memiliki dampak tak langsung pada kesehatan fisik dan juga pada sikap mental kita terhadap kehidupan. 
Sekalipun satu kelenjar tidak berfungsi, kerugian yang nyata dalam kesehatan kemungkinan akan dialami. Oleh karena itu, adalah sangan penting bahwa jaringan ini dipelihara pada keadaan yang maksimum. Organ-oragan tubuh yang sakit dapat diperbaiki, diremajakan kembali, dan didorong untuk melakukan tugas normal mereka melalui latihan āsana yang teratur (Suadnyana, 2020).

Otot dan tulang, syaraf, kelenjar, jalan pernafasan, pembuangan, dan sistem peredaran darah diserasikan sehingga semua sistem jaringan tersebut saling membantu. Āsana membuat tubuh lentur dan mampu mengatur dirinya dengan mudah untuk mengubah lingkungan. Fungsifungsi pencernaan dirangsang agar jumlah yang tepat dari getah-getah pencernaan (air liur, ensim dan lain-lain) mengalir. Sistem simpati dan parasimpati dibawa kedalam keadaan yang seimbang agar organ-organ dalam yang mereka kendalikan tidak terlalu aktif maupun kurang aktif.

\section{Manfaat Bagi Mental}

Asana membuat pikiran kuat dan mampu menahan rasa sakit dan kemalangan. Daya penentu dan konsentrasi perlu dikembangkan. Keseimbangan dan vitalitas menjadi keadaan pikiran normal setelah melakukan latihan asana yang teratur. Akan mampu menghadapi penderitaan, kegelisahan, dan masalah-masalah dunia dengan tenang tanpa terganggu. Keseimbangan pikiran dikembangkan, hidup menjadi mudah, dan berbagai kesulitan menjadi batu loncatan untuk menyempurnakan kesehatan mental. Latihan asana melepaskan berbagai kemampuan terpendam sehingga seseorang mampu menyebarkan kepercayaan dan membangkitkan orang lain dengan ucapan, tingkah laku, dan perbuatannya.

\section{Manfaat Bagi Spiritual}

Asana merupakan langkah ketiga dalam delapan tahapan jaaln raja yoga yang tujuannya adalah untuk membuat tubuh kita mantap bagi teknik-teknik yang lebih tingi dari pratyahara (penarikan indera-indera), dharana (konsentrasi), dhyana (meditasi), yang membawa pada puncaknya, yaitu Samadhi (realisasi kosmis). Dalam hatha yoga, yang diperhatikan lebih mendalam dengan menyiapkan tubuh pada teknik-teknik spiritual yang lebih tinggi, terutama ditujukan untuk menyucikan tubuh melalui asana. Semua teknik-teknik tersebut digambarkan secara rinci dalam naskah kuno seperti Hatha yoga Pradīpika dan Gheranda Samhitā. Meskipun asana sendiri tidak dapat memberikan kesadaran spiritual tetapi asana merupakan tahapan pada jalan spiritual.

Pelatihan Hatha yoga bermanfaat untuk membangun integritas diri daripada masingmasing dosen dan pegawai yang meliputi moralitas, kejujuran, etika dan membangun revolusi mental. Dengan memiliki integritas Dosen dan Pegawai akan mampu membangun integritas mahasiswa di lingkungan Universitas Ngurah Rai. Melalui pelatihan Hatha yoga juga akan 
mampu membangun kesehatan fisik, mental dan spiritusl bagi masing-masing Dosen dan Pegawai di lingkungan Universitas Ngurah Rai. Secara rinci bahwa setiap gerakan dalam Hatha yoga memiliki manfaat masing-masing, adapun manfaat dari gerakan Hatha yoga yang dilakukan dalam pelatihan Hatha yoga bagi Dosen dan Pegawai di Universitas Ngurah Rai Denpasar adalah sebagai berikut :

\section{a) Latihan Pranayama}

Secara umum latihan pranayama bermanfaat untuk menguatkan organ internal serta membersihkan diri dari dalam sehingga pikiran akan menjadi tenang. Sedangakan secara khusus manfaat pranayama yang dilakukan dalam pelatihan Hatha yoga bagi Dosen dan Pegawai di Universitas Ngurah Rai Denpasar adalah sebagai derikut :

1) Nādi Sodhana Prānāyāma bermanfaat untuk membersihkan nadi-nadi dalam tubuh kita. Semua alur prana dibersihkan dari berbagai rintangan. Aliran prana dalam ida dan pinggala nadi sisamakan. Jaringan darah dibersihkan dari berbaagi racun dan seluruh tubuh dipelihara oleh persediaan oksigen tambahan, dan karbon dioksida dikeluarkan secara efesien.

2) Abhyantar Prānāyāma bermanfaat untuk menyembuhkan sesak nafas.

3) Bahyantar Prānāyāma bermanfaat untuk meningkatkan kekebalan tubuh.

4) Anulom Vilom Prānāyāma bermanfaat untuk menyeimbangkan tekanan darah pada tubuh.

5) Bhramari Prānāyāma bermanfaat untuk menghilangkan ketegangan otak , menghilangkan kemarahan, kegelisaan, dan frustrasi serta mengurangi tekanan darah.

6) Kapālabhāti Prānāyāma bermanfaat untuk mengecilkan perut atau mengurangi kegemukan. Membersihkan daerah otak bagian depan, pikiran dan pandangan secara otomatis terhenti, membiarkan pikiran beristirahat dan menjadi segar kembali.

7) Bhastrika Prānāyāma bermanfaat untuk membersihkan/menguatkan paru-paru dan menghilangkan stress. Meningkatkan nafsu makan dengan memperbesar api perut.

\section{b) Latihan Gerak Surya Namaskara}

Gerakan surya namaskar meiliki manfaat yang sangat baik untuk tubuh, manfaat yang didapatkan dari melakukan gerakan yoga suryanamaskar ini yaitu untuk menguatkan organ tubuh utama, keseluruhan otot, meningkatkan kelenturan tulang dan sendi-sendi, meningkatkan konsentrasi, menenangkan pikiran serta melancarkan sistem pencernaan.

\section{c) Latihan Asanas Lepas}

Asanas lepas memiliki manfaat masing-masing sesuai dengan gerakan yang di lakukan, adapun manfaat dari asanas lepas yang dilakukan dalam pelatihan Hatha yoga Bagi Dosen dan Pegawai di Universitas Ngurah Rai Denpasar adalah sebagai berikut : 
1) Tadāsana : Bermanfaat untuk membentuk keseimbangan fisik dan mental. Sangat bagus untuk sakit kepala.

2) Trikonāsana : Gerakan ini sangat baik untuk kesehatan ginjal, menghilangkan sembelit serta memijat urat syaraf tulang belakang.

3) Pascimottanasana Posisi Berdiri : Gerakan ini bermanfaat untuk membangkitkan energi Kundalini dan membuat wajah bersih.

4) Dhruvāsana : Gerakan ini sangat baik untuk membangun keseimbangan, konsentrasi, kestabilan tubuh dan menenangkan.

5) Natarajāsana : Bermanfaat untuk menyeimbangkan jaringan syaraf, membantu dalam pengendalian jasmani dan konsentrasi mental serta melemaskan kaki.

6) Garudāsana : Baemanfaat untuk menjaga keseimbangan sistem syaraf, meningkatkan konsentrasi dan dapat meningkatkan kontrol terhadap tubuh.

7) Pascimottanasana Posisi Duduk : Bermanfaat untuk mimijat organ pencernaan, mengatasi sembelit dan membantu menghancurkan lemak di perut

8) Akarnadhanurasana: Bermanfaat untuk menyelaraskan oragan-organ perut, meregangkan punggung dan menguatkan kedua otot lengan sebelah atas serta pergelangan kaki. Mengobati perut kembung, sangat bagus untuk penderita tekanan darah rendah dan darah tinggi.

9) Gomukhasan : Bermanfaat untuk kesehatan jantung serta dapat membantu menghilangkan diabetes, sakit pinggang, bahu dan leher yang kaku, berbagai penyakit seksual, sangat bagus untuk penyakit-penyakit mata dan tangan akan berfungsi sempurna.

10) Marichyāsana : Bermanfaat untuk menyegarkan susunan saraf pusat yang terletak pada tulang punggung bagian belakang, menjaga sendi-sendi tulang punggung agar tetap elastic, kuat dan muda, serta melepaskan ketegangan pada leher dan punggung.

11) Ustrasana : : Gerakan ini sangat baik bagi sistem pencernaan dan sistem reproduksi.

12) Uttanapadasana : Bermanfaat untuk menguatkan otot perut dan sangat baik untuk tenggorokan.

13) Halasan : Berfungsi untuk mengatur fungsi organ perut, ginjal, hati dan pankreas. sangat baik untuk mengurangi lemak pada pinggang dan melenturkan tulang belakang,

14) Sarvangasana : Bermanfaat untuk memijat kelenjar gondok sehingga dapat memperbaiki peredaran darah.

15) Cakrāsana : gerakan ini sangat baik bagi seluruh jaringan syaraf, sangat baik bagi penderita paru-paru basah, mata, telinga dan kelenjar serta sangat baik untuk melenturkan tulang belakang. Dengan asana ini seluruh energi badan akan berputar seperti roda. 
16) Bhujangāsan : Bermanfaat untuk mengatasi masalah pada organ reproduksi pria dan wanita.

17) Salabhāsana : Bermanfaat untuk meyelaraskan fungsi hati, ginjal, usus dan pancreas.

18) Dhanurasana : Bermanfaat untuk memijat organ dan otot perut sehingga dapat mengatasi masalah pencernaan dan kelembaman hati.

19) Savasana : Mengendurkan seluruh bagian tubuh baik secara fisik dan fisikologis, mengatasi ketegangan otot, susah tidur, dan baik bagi orang yang tidak bias mengendalikan pikiran.

\section{PENUTUP}

Proses pelaksanaan pelatihan Hatha yoga Bagi Dosen dan Pegawai di Universitas Ngurah Rai Denpasar dilaksanakan setiap hari kamis pagi di Universitas Ngurah Rai Denpasar. Dalam proses pelaksanaan pelatihan Hatha yoga bagi Dosen dan Pegawai di Universitas Ngurah Rai Denpasar ada delapan taahpan yang di lakukan, adapun tahapan tersebut yaitu: (1) Salam pembuka dan doa bersama, (2) Latihan Pranayama, (3) Pemanasan gerak, (4) Latihan gerak Surya Namaskara, (5) Latihan asanas lepas, (6) Savasana, (7) Meditasi dan (8) Hasya Yoga (penutup). Manfaat pelatihan Hatha yoga bagi Dosen dan Pegawai di Universitas Ngurah Rai adalah untuk meningkatkan kesehatan fisik, mental dan spiritual. Disamping itu pelatihan Hatha yoga bermanfaat untuk membangun integritas diri daripada masing-masing Dosen dan Pegawai yang meliputi moralitas, kejujuran, etika dan membangun revolusi mental.

\section{DAFTAR PUSTAKA}

Koentjaranningrat. 1994. Metode-metode Penelitian Masyarakat. Jakarta: Pt Gramedia Pustaka Utama.

Moleong, Dr. Lexi J.1990. Metodelogi Penelitian kualitatif. Bandung: Remaja Rosdakarya.

Purwadipta, Ida Bagus Gede Wahyu. 2014. Nilai-nilai Pendidikan Agama Hindu Dalam Kakawin Mayaspati. Denpasar: Fakultas Pendidikan Agama dan Seni, Unhi.

Ritzer, George. 2004. Teori Sosial Postmoderen. Yogyakarta: Kreasi Wacana.

Sarasvati, Svami Satyananda. 2002. Asana, Pranayama, Mudra dan Bandha. Surabaya: Paramita.

Sivananda, Sri Svami. 1998. Pengetahuan dan Pengendalian Prana (Pranayama). Surabaya: Paramita.

Somvir, Dr. 2009. Yoga \& Ayurveda, Selalu Sehat dan Awet Muda. Denpasar: Sampurna printing.

Suadnyana, I. B. P. E. (2020). Nilai yang Terkandung dalam Gaguritan Mituturin Angga. Sanjiwani: Jurnal Filsafat, 9(2), 165-178. 
Suadnyana, I. B. P. E. (2020). Sang Hyang Sambah dalam Ngusabha Sambah di Desa Pakraman Pesedahan, Manggis, Karangasem (Kajian Bentuk Fungsi dan Makna). Sanjiwani: Jurnal Filsafat, 9(1), 87-96.

Suyomukti, Nurani. 2013. Teori-teori Pendidikan. Jogjakarta: Ar-Ruzz Media.

Wiana, Drs. I Ketut. 2007. Tri Hita Karana Menurut Konsep Hindu. Surabaya : Paramita.

Widjaja, I Wayan Sadha. 2007. Yoga Dalam Ganapati Tattwa. Denpasar: Fakultas Ilmu Agama, Unhi.

Yasa, I Wayan Suka, dkk. 2011. Roga Versus Yoga Perspektif Ayur Weda. Denpasar: Widya Dharma.

Yasa, I Wayan Suka. 2011. Yoga Marga Rahayu. Denpasar: Widya Dharma. 